\title{
NOTES FOR THE READER
}

The chapters in this volume were first published in a range of books and journals. In order to make the chapters more consistent I have standardised the transliteration of Arabic, spelling (British rather than American English), italicisation, citation system, and footnoting. The transliteration of Arabic follows the system of the International Journal of Middle East Studies and the third edition of the Encyclopaedia of Islam. Dotted consonants and long vowels are not included for personal names and toponyms, though 'ayns (') and hamzas (') have been maintained. English spellings are employed for well-known towns and cities (Cairo, Jerusalem, Mecca, Medina, and so on). Arabic words that are in use in English are left unitalised. I have not attempted to standardise the names of Greek primary sources, and in some cases have opted for older versions rather than those employed in more recent scholarly writing (for example, Chalcocondylas rather than Chalkokondyles and Ducas rather than Doukas). Unless stated otherwise, the dates are given according to the Common Era.

The pagination of the original publications has been marked into the texts of the chapters enclosed in square brackets. In places where the numbering in square brackets is not sequential (i.e. missing one or more pages) it is because the pages of the original publication contained only figures/photographic plates. Some maps have been replaced and a few photographs have been cut where it has proved unfeasible to reproduce them again. I have updated the material in the footnotes to account for new publications and, where necessary, corrected inaccurate assertions. 
